\title{
Ssciendo
}

10.2478/abcsj-2021-0016

\section{The Future as a Scenario of Hospitality in Ali Smith's There But For The}

\author{
ANDREI BOGDAN POPA \\ Babeș-Bolyai University, Cluj-Napoca, Romania
}

\begin{abstract}
The purpose of this essay is to demonstrate how Ali Smith's novel There But For The (2011) foregrounds a temporality in which the scenario of hospitality is encoded into the characters' perception of the future, while the welcoming scenarios in which they engage are themselves marked by the awareness of futurity. To this end, I rework Levinas's equation of the future as the Other, as well as Derrida's notions of conditional and unconditional hospitality, of the future as the expected/ unexpected event, and of "choratic space." The subsequent analysis of the novel proves how these notions are thematized both through the characters' inner and intersubjective discourse, and via the authorial construction of imagery and the deictics of the spaces they inhabit. As such, the characters' conversations bear the marks of an uncertain causality springing from the welcoming scenario; attitudes towards futurity are faced with the disquieting awareness of the conflict between the expected and the unexpected event; while the choratic space acts as the possibility of an ethical reaction to the strangers' singularity, through a linguistic reorientation which employs the contingency of the linguistic sign as a site for hospitality.
\end{abstract}

Keywords: futurity, conditional hospitality, unexpected event, choratic space, contingency, thematization, singularity

Ali Smith's novel There But For The (2011) was published during a time when the United Kingdom was still reeling from the Great Recession of 2007-2009, and, as a cultural document of the era, the text can be said to 
reflect the lingering sense of a bleak societal outlook sparked by the financial crisis. As a work of literature, the text nonetheless develops a complex thematization of futurity beyond its historical context. This essay aims to prove that Smith's novel constructs a temporality which simultaneously encodes the scenario of hospitality into the self's perception of futurity, and recalibrates the present welcoming of the stranger towards the effects such a meeting will have in the future. The novel projects a temporal dyad of causality and unpredictability predicated on a system of narrative ethics that renews itself and its language with each singular situation of hospitality. A moral response to the predictable and unpredictable strangers or hosts of the future might turn out to be contingent upon such an ethical mode of thought which, through narrative fiction, trains the self to operate with notions of responsibility and conditionality. I demonstrate how characters reinvent their own language and temporal consciousness in order to accommodate the stranger, be it in the form a stranger proper, a visitor, a familiar other whose identity has suffered great transformation, or the traumatic subconscious resurgence of a departed alterity.

In analyzing the novel, I discuss how the relation between the characters' perception of futurity and the deixis in scenarios of hospitality changes across the chapters, as they are narrated through each of their respective inner monologues. These discourses unfold during the social and media frenzy following an upper-class dinner party where an uninvited guest, ethical consultant Miles Garth, locks himself in the spare room of the hosts and refuses to come out. However, each of these characters are, to a certain extent, outsiders to this bourgeois world. Anna struggles to define her future under deep financial strain and enters the narrative as Garth's only identifiable contact, though they had only had a brief friendship tens of years ago; Mark, one of the invited guests, dreads the outcome of this social occasion and brings Miles along, although they had just met; the dying May Young has dementia and had bonded with the famous uninvited guest ever since his childhood, in the wake of a tragedy; finally, Brooke, a ten year old prodigy whose future is jeopardized by the racism and economic austerity raging around her, finds solidarity with the 
man in the spare room by engaging in a welcoming scenario that bypasses notions of private property and social convention.

Futurity, Hospitality, and Fiction

In order to demonstrate Smith's encryption of hospitality into futurity, and vice-versa, I focus primarily on the triad she establishes between narrative ethics, thematization, and linguistics. Thus, the interdependence between "the future" and "the Other" (Levinas, Time 77) is coded into the deixis of welcoming scenarios, and surfaces at the level of the character's discursive material. Meanwhile, a parallel can be drawn between Derrida's dichotomy of conditional versus unconditional hospitality (Rogues 149) and the decisions, as well as the physical dynamics, of the characters. This proves that the acts of hospitality that Smith constructs reflect key ethical frameworks that can be provided by fiction, such as the absolute singularity of the Other and of the Event, as in Derek Attridge's conception of the creative writing process (300).

Smith's thematic preoccupation with futurity has been highlighted by Mark Currie in his essay, "Ali Smith and the Philosophy of Grammar," where the theorist investigates the nature of the relation between "the strangeness of the future and the future as blankness in writing" (48) throughout the author's oeuvre. However, my own argument varies from Currie's perspective by demonstrating that it is through an explicit thematization of hospitality that the future is encrypted in the scenarios that Smith produces. Thus, she envisions the future less as "opacity" (Currie 51), and more as a welcoming of the Stranger as the expected unexpected, as a complete disruption. Therefore, while I agree with Currie's insightful assertion that Smith's fiction "makes metaphors out of linguistic categories" which "help define the method of a fictional enquiry into the comprehension of time," I nonetheless argue that "the strangeness of the future and the future as blankness" (48) in her writing are concepts that belong to the realm of hospitality. In this conception, visible and invisible Strangers cohabit the future as expected and unexpected Events. The logic behind this interpretation is informed by what Currie convincingly describes as Smith's championing of the metaphor as a 
philosophical tool, and the "question of the visibility of the future" as an "area of this demonstration" (51). However, my argument starts precisely from the omission of the Stranger from his statement, enlightening and useful as it might be, that: "the principal interest lies in the relationship between writing, as visible language, and futurity as the yet unwritten" (Currie 52). My reading of the novel seems to be verified by Patrick O'Donnell's briefer, subtler observation regarding Hotel World and The Accidental: "Smith's novels thus point toward alternative futures in lives that include alterity and proceed otherwise" (89). This "inclusion," I argue, is thematized and greatly complicated within the scenario of welcoming, with all it entails. Furthermore, for O'Donnell, Amber is:

the stranger without and within who brings both knowledge of self and a knowledge alterity that opens out spatially onto a planetary reality and temporally onto a future that seems both certain in its existence and radically indeterminate in its direction. (O’Donnell 99)

In my reading, the characters of There But For The are subsumed to a "[radically indeterminate] direction" and a "[certain existence] of the future," and a blueprint of their presence is already in the consciousness of the host before they have even arrived, as the "knowledge of the self and [of] alterity" (99) is created through the intersubjective, creative process of welcoming. My argument therefore represents a natural extension of these previous perspectives. These brief interpretative leads are elaborated by focusing on Derrida and Levinas's respective views on hospitality, as well as futurity.

I take my cue from Derek Attridge's recontextualization of Derrida's concept of two opposing "versions of human existence" - one in empirical succession, the other, impacted upon by the unpredictable - into any situation which admits these two alternatives: "life requires a transaction, a negotiation between the unconditional and the conditional" (300). Toward the conclusion of his 2015 theoretical text, The Work of Literature, Attridge asserts that literature is the domain where "the unconditional has to be realized as the conditioned" (304), where the new is folded into what is already in existence, respecting and making space for the absolute singularity of the Event: since absolute newness cannot 
actually have an impact on the culture, the artist has to make space for the hitherto unthinkable, the unpredictable other, through a rearrangement of the techne which is, to varying degrees, already familiar to the public. This aporia of hospitality gives us the opportunity to point out how the deixis of the welcoming situation relate to language. And to do this, we should return again to Derrida: first, to his musings upon the double meaning in "to call" ("heissen") as both "to name" and "to invite," "to welcome"; second, to his assertion of the "common origin between hostis as host and hostis as enemy, between hospitality and hostility" ( $O f$ Hospitality, 15). In a way, this attention to paradox might be a requisite for the "future language" of democracy which keeps unconditional hospitality as its main ideal. It illuminates the semantic sedimentation of what being hospitable has meant throughout history and how these unresolved tensions in origin of meaning might circumvent reason in both constructive and destructive ways. This fundamental paradox in ethics can be articulated not only through a proliferation of contradictions and puns in the fabric of the text, but also through coincidences in its narrative and ambivalent attitudes. Smith's novel seems to be driven by a similar impetus: the unforeseeable future can be welcomed through a linguistic system whose evolution is scaffolded in an original conception of unconditional hospitality. The transition from ideal unconditional hospitality to the reality of a conditional welcoming scenario recalls another of Derrida's terms, that is, the "choratic space," wherein contingency manifests itself and creates "an opening to that other to come (à-venir) [as well as] to the future (l'avenir)" (Dick 119). This is precisely the space which precedes the definition of the Event and witnesses its arrival. However, such an opening does also share this space with hospitality. They are both prior to philosophical principles and to the realm of ethics itself. The arrivant, then, is marked both by singularity and by neutrality, while her arrival is awaited but not expected by the host. This is what we mean by 'hospitality to the Event', but also to the future: "to the event that cannot be awaited as such, or recognized in advance therefore, to the event as the foreigner itself, to her or to him for whom one must leave an empty place, always, in memory of the hope and this is the very place of spectrality" (Specters of Marx 82). 
To expand upon this description of the future, we must return briefly to the issue of language. Any decision to offer hospitality is contingent upon the degree to which language allows itself to be reinvented, and thus to clear the path for new rules. This should be taken as referring both to hospitality as a literary dimension, and to hospitality in general, where the former can be investigated through Levinas's concept of the Saying as "my exposure without reserve to the other," to which he also equates "sincerity" (Otherwise xv). By this, he means that no face-to-face encounter is capturable in the Said, in how it can be put into words empirically or descriptively. In this ethical matrix, language strives to secure a vehicle for acknowledgment and acceptance within intersubjective communication. This new linguistic system, therefore, has to be poetic, to accommodate the absolute singularity which constitutes the arrivant and the Event therein. Importantly, this "arrival" triggers an "interruption of the self" (Dick 90). In fact, this interruption is so violent that it is already a priori accepting of any outcome, good or bad, resulting from the visitation. A society is as hospitable as it is willing to be open to the humanity, as well as the radical evil potentially brought by hospitality. It is an acceptation of history as essentially ruptured, bereft of any predetermined narrative or ending. The unpredictable future is also that to which the messianic hope must be radically hospitable.

Finally, in order to elucidate the political drive behind such literary endeavors, Attridge's conception of literary ethics is of imperative help. Literary invention, in Attridge's understanding, is, importantly, "both the process and the artefact" (39), by which he means an original creation that transforms its readers in such a way that those transformations reverberate throughout the culture and introduces new possibilities for future works. What, then, are the ethical implications of an invention which sets itself the task of dealing with contemporary socio-political issues? To what extent can it deal with recent developments in areas of activity which threaten quality of life and human existence itself? Levinas contends that the essential ungraspability of the future renders its exteriority totally surprising, which differentiates it from spatial exteriority. This is the spatio-temporal crux of the scenario of hospitality in the contemporary age, and Smith's 2011 novel has never seemed more prescient than it does 
today. Under the pressure of climate change and late-stage capitalism, both spatial and temporal exteriority can be ascribed to a higher degree of conditionality than usual, but unconditional hospitality, though impossible under any real-life conditions, still guides the law through a temporality which is directed to alterity. The future, then, is that which cannot be grasped, which merely happens to us, the stranger we have to welcome: "The other is the future. The very relationship with the other is the relationship with the future. It seems to me impossible to speak of time in a subject alone, or to speak of a purely personal duration" (Levinas, Time 77). I claim that, in these two novels, Smith aims to problematize political aestheticization by envisioning futurity through the Other, and by narrativizing this very process. In order to historicize the present, it must be wary of how the understandably prophetic and conditional discourse of futurity (whether it in ecocriticism, geo-politics, or economics) is liable to affect the very thing which makes conditional hospitality possible, that is, unconditional hospitality. However, in order to redirect futurity towards the other, the other has to be seen as futurity, which means to re-envision the singular event in every scenario of hospitality. This involves a shift in how we imagine communal living, generational conflict, identity, and art. The language of hospitality can never stay the same.

\section{Encoding Futurity into the Scenario of Hospitality}

Futurity as a dimension of recent British fiction has been discussed by Peter Boxall, who asserts that, with Autumn (2016), Smith proves her Dickensian "capacity to extend oneself in time" in order to "bridge the gap between the future and the past opened by the revolutions of Trumpism, and of Brexit" (291). He also contends that, for Smith, in order for us "to be a citizen of the world now, we need also to be a citizen of nowhere, the no place that has haunted the novel's utopian imagination since Thomas More's 1516 work Utopia” (Boxall 292). However, I think that Derrida's notion of the choratic space can not only facilitate a more precise assessment of the way in which the temporality of There But For The foreshadows the politics of Autumn, and what Boxall now sees as "the gulfs between [the past and the future], ... that may grow out of our 
collective past, but which does not belong to it, or follow from it" (292). This intergenerational "communal nowhere" is precisely the site in which he argues that we can "craft the forms in which we can look to the future" (277), but I think that we need to envision this very gulf through the responsibility we have for the Other.

To demonstrate this point, we can simply look to Miles's meetings with the other characters. The first interaction Miles has with Anna (or with anyone else in the novel, for that matter), is marked with futurity, as he jokingly refers to their present dialogue in its singularity: "There was once a girl twenty years in the future who was totally unable to communicate except by rolling her eyes and saying only the word actually" (There 33). When Anna later concludes that he "reinvented" her, it subtly suggests that Miles in fact reinvents himself and the language of welcoming according to the singularity of each of the characters to which the chapters are ascribed via free indirect speech. Importantly, this conversation comes to Anna's mind as a memory that is triggered by the word "anarchy," which is a pun on her name made up by Garth: "You'd be Anna K in the UK." Throughout this excursion into her memory, Miles is repeatedly the one who "make[s] her join" (There 40), and it all starts with a relentlessly pun-filled conversation. This summoning of individuals into community is metaphorized into Miles's habit of "throwing bits of bread at the water and watching for the mouths of the fish to appear, to open and close as if detached from any actual fish-bodies, at the surface" (There 48) - a game in which he also engages with Anna. However, it is important to note that Anna's "task" in the beginning of the novel ironically mimics this scenario: it is she who has to make Miles "[re]join" the outside world. Importantly, Miles is the one who stresses the importance of free movement to her early on. In their first conversation, he shares with her his observation that "[she]'d rather be there than here" (There 43), as Anna is having a hard time fitting in with the English kids. Once he retrieves her passport (he, too, by trespassing), he tells her "There you are" (There 45). Nonetheless, the agency gained by Anna as a result of her interactions with Miles hints at the implication that his notion of ethical agency always involves a "readiness to not be ready" (Attridge 300) to welcome the inalterably singular Other. This implication gains potency when his submission for the "Imagine Britain in 20 years" contest 
turns out to be temporal relocation into a fictional sci-fi future of a personal memory of which we find out much later on in the text (the death of his childhood friend, Jennifer; he even keeps her name in the story). In this narrative that he creates, Miles Garth sees the future itself as the container of a nostalgia born out of the present ("There was once, and there was only once, he says. Once was all there was" (There 40), and every scenario of hospitality in which he finds himself is marked by this fact. This also reverberates into Anna's decision to cut out the Lees and head straight for his window, as well as into the flourishing of his friendship with May, in the wake of their shared grief.

The two scenarios of hospitality with which Anna is faced in this memory thematize the aporia of hospitality, the movement from "hostis as host" and "hostis as enemy" (Derrida, Of Hospitality 15): on the one hand, the artificial sociality of the predominantly British school group of pupils that have won the competition; on the other, the more ethically concerned hospitality of Miles. The punning in which the two initial strangers engage breaks the tension of the potential hostility that can be triggered by miscommunication. Smith therefore traces the relation between the arbitrary linguistic sign and the deictics of welcoming in literary fiction. Indeed, these interactions bear traces of an unconditional opening being folded into the conditional.

\section{Encoding Hospitality into the Future}

It becomes clear that this encoding of futurity into present hospitality is something that echoes throughout the characters' perceptions of their own life that is to come. In a pointed thematization of the self's perception of futurity, both Mark and Anna are respectively said to "[sit] in the future" (There 46)- that is, the future of their memories. Mark himself is haunted by an impossible future just as much as he is by a tragic past. He discovers he is gay three years after his mother's passing, so that he does not know how she would have reacted to it, and at one point he invokes an anecdote regarding old Queen Elisabeth's despair at her infertility ("'The Queen of Scotland is a mother of a fair son, and I am but a barren stock"”) (There 60). This same anecdote also announces another key feature of Mark's future-as-hospitality: as a gay man who has lived 
through the AIDS epidemic, he is guided by a drive for survival ("even when she met her demons, she was what you'd call a survivor, that old Queen" (There 60). This fact is made all the more apparent when, in one memory, Aunt Kenna tells him: "Animals, Mark, have no use for nostalgia ... It is not a tool for survival, my darling" (There 120).

However, as in the case of Miles's sci-fi story, Mark's future is continuously coloured by things he spontaneously remembers from long ago in his past; his survivalist nostalgia comes in bursts of long forgotten and still not remembered memories which are narratively rendered to us side by side with experiences stored in his psyche that he has not even remembered yet but still guide his actions and decisions. As he stands behind the door, hearing the guests talk about his mother, the narrator indicates that "in his muscles he is thirteen years old and the hush is about to happen all over again ... he'll also be the one whose mother ... went of her own accord" (There 117). At another point, Miles tells Brooke that his mother died just before the Cuban Missile Crisis, which, he notes, "was very serious" (There 129), thus complicating an already uncertain life that lay ahead. The future is already encrusted into the traumatic memory, just as it is into the nostalgic one, and both categories display memories which have to do with scenarios of hospitality (his days at school, his first love). Thus, the archival memory stored in one's consciousness always comes into play as a defining agent in future scenarios of hospitality, since the memory already encrypts in itself the experiences that followed it. More importantly, the shadow of the Cuban Missile Crisis and the AIDS epidemic project expected scenarios that would orient any welcoming scenario and its outcomes toward the oblivion of nuclear destruction, respectively disease and humiliation.

These uncertain and troubling possible futurities that inform Mark's identity come in subtle contrast to the irruption of unpredictability into the complacent, bourgeois reality inhabited by the Lees. As we learn from the newspaper article written by Gen herself, the couple is disturbed by both the uncertainty of the future ("Who knows what the future holds? Every new day I wake full of the possibilities of change"'), and the spectrality which encroaches upon their space of living ("'It sounds uncanny and feels like I imagine being haunted must feel like"”) (There 79). Eric's DVD collection of "sci-fi classics of the fifties and sixties" (There 79) that 
Miles probably does not watch also adds to the theme of futurity and its promise of inevitable, but as of now, unknowable strangers. Indeed, perceptions of what is to come have always had a direct impact on scenarios of welcoming. Miles's dwelling in the Lees' spare-room only unearths this inescapable, disconcerting reality of time and being. Smith thus points both to the detrimental effects that the cautious optimism elicited by an expected Event can have on one's definition of futurity, as well as the commodity fictions that breed self-centered passivity toward the well-being of the Other. In the logic of late capitalism, any "exposure without reserve to the other" (Levinas, Otherwise xv) and the acceptance of self-interruption are liable to compromise one's desired selfactualization and upward mobility. Here, there is no room for the uninvited guest, and the culture evolving around this conception of responsibility will inevitably inform any aestheticization of politics. It is in this light that we should view Smith's problematization of the very dialogue around hospitality, whether it be regarding asylum seekers or the homelessness crisis that plagues Britain to this day.

\section{Thematizing the Hospitality/ Futurity Dyad}

So far, the two sides of the deictic dyad of hospitality and futurity have been explored separately. In the chapter of the novel that focuses on May Young, these two dimensions of the welcoming scenario become inextricably linked. Despite being thoroughly informed by grief, past trauma, survivor's' guilt, and a deeply rooted, longstanding aversion to authority, May's chapter best illustrates the ways in which the future is envisioned as a complicated, difficult scenario of hospitality, and how this welcoming of the stranger is in itself a repository which houses the inevitable passing of past and future experience into the decisions regarding, and reactions to the unexpected visitor.

At its centre, May's treatment of the stranger stems from her past collisions with the unpredictable and unexpected. Firstly, as she rides her bike through a pathway full of holes of which she is aware, only to get hit by "the dark taking a shape, going solid out of nowhere in front of her" (There 164). However, she is keen to differentiate this experience from that of "when the bomb hit the ball-bearing factory next door to the shop 
and she'd been blown across the room backwards and hit the wall behind her." This time, "she'd just gone headlong with her eyes wide open into it, that she'd done it herself somehow, hit the dark" (There 164). Therefore, in May's case, the totally unexpected event at first takes place both within and outside herself. The "dark" can be read as Derrida's choratic space, or Boxall's "untensed time" preceding an "unreadable future" (Boxall 280), but what is of imperative importance here is Young's "say" in the matter: the feeling that she had done it to herself will inform her later guilt regarding her daughter and the rejection of her friend. Both she and Jennifer have independent, inquisitive personalities: the latter tries to find out "what humans [are] for," at a very young age, in the form of a survey. The answers are stereotypical to their age group, but May's answer, "to look after each other" (There 173), is indeed consistent with her behavior.

However, her Greatest Generation-tinted view of human interaction makes her especially unprepared for the unexpected: dryly, she proclaims to herself that people in her youth were "keeping it quiet, is what we were. We had to be. It was the way. Them with their jet-age" (There 168). This explains May's second unexpected event, transitioning to the intimate sphere during the sewing-machine scene: she is working on new clothes, pressing the pedal, when Jennifer tells her about Miles's apparent confession of having been molested. This display of vulnerability and fragility triggers May into forbidding her daughter from ever contacting Miles again. Jennifer resists, at first, but then: "she decides against it. She stops herself. She stands up. She leaves the room, closing the door behind her" (There 168). This behavior echoes both May's resistance to speech in hospital, and Miles's decision to leave the dinner table at the Lees'. The third unexpected event is her daughter's sudden, freak heart attack death, something unintentionally foreshadowed by the girl herself at a much younger age, through her vocalized fears regarding spontaneous combustion ("If I spontaneously combust I'll send my arms and legs by themselves to the park to watch you do it" (139).

All these memories constitute May's archival identity in such a way that she encrypts them into future scenarios of hospitality, unexpected or not. This particular type of identity is archival because it subsumes neurological, subconscious clusters of memories that are, in themselves, stored as data. The successive bursts of these individual memories are that 
which can constitute a narrative identity. Soon after her death, it happens that Miles, the boy she had shunned but who reached out to her in the aftermath of their shared grief, starts leaving her gifts each year on the day of her daughter's passing, which it is suggested, causes May to eventually invite, or call him in. This creates a shared, somewhat safe and predictable future of mourning, which will inform Miles's calling of Anna into society. Moreover, Young points out in her interior monologue that old age "brought a whole other person with it, a stranger whose wrists were old" (There 137), which is why we can read the "dark" against which she causes herself to hit her bike as the space in which future meaning is about to be created in the encounter with alterity, that is, the choratic space. We can also observe a certain conflict between aversion to conformist, monotone authority on the one hand, and a fear of the unexpected on the other. Essentially, this fear can be read as the unease that comes with acknowledging that May from the future will be a stranger to May from the past. It is also this stranger who will meet the unexpected event, be it something abstract or another stranger in the flesh. In addition, we can read a redirection away from unreflective movement and toward a certain will to agency via stasis in the imaginative transition from the bicycle to the sewing machine, to Miles's use of the Lees' exercise bicycle.

For May, the most important future Event at the time of the narration is that of her own death. She was there when her mother died and observed that "that man's back," followed a few years later by her husband's death when he, too, saw a "man in a suit." Both times May turned and saw "nobody there" (There 141). Moreover, this last phrase recurs poignantly throughout her chapter. Firstly, her son renounces religion because God "wasn't there when Jennifer" died, to which Young, in her inner monologue responds that "She just went. Nobody saw. There's nobody there to see" (There 151). Secondly, each time she calls her living daughter and the answering machine comes on (as they do not want to talk to her), she eerily, vocally asserts: "Nobody there" (There 160). In addition, there's also the impending threat of being taken away to the dreaded "Harbour House" residential facility, another instance of a restrictive, artificial, organized social community that we also saw in Anna's European Tour and the infamous dinner party. Therefore, each 
new stranger with whom May crosses paths is seen through these three prisms: the personification of death as "the man in the suit," (There 167) the potential yielding to forced human interaction, as well as even less personal agency, and finally, the possible absence of any figurative or perceptible manifestation of her death, which would be the total and absolute unknown. Thus, she mistakes Gen's satirically millennial daughter for "the man in the suit" and eventually tells her: "You've to take me" (There 171). When the girl asks her for the location, her response is "You know" (There 171). It can thus be concluded that May's perception of the deixis basing the welcoming situations in which she finds herself bear with them the semantic and sensuous effects brought upon her perception by the past trauma of her daughter's death.

\section{Tracing the Choratic Space}

So far in the novel, all three characters whose points of view filter the events of the novel have reckoned with different anxieties regarding their future: Anna has to find meaning despite unemployment and disillusionment with late-stage capitalism; Mark dreads the Lees' dinner party; May is facing death. Nonetheless, it is Brooke's foreboding that is the most affecting. Her future is split between two temporal milestones: on the one hand, her 10th birthday, another step from innocence to experience and a moment she is expected to share and celebrate with those around her; while on the other, the return to school, where her racist teacher will most likely continue to verbally and physically assault her for being too intelligent. She is living in a country marred by austerity and racial inequality, as well as by the natural contingency of the natural world. This makes it so her future is as ripe for fulfilment, vitality and happiness, as it is for disenfranchisement, violence, and even early death. These are all issues that children who do not face oppression already deal with. However, Brooke's fears are greatly augmented by the intolerance that haunts her envisioning of the future, and this in itself is greatly tied to the issue of hospitality: she is not only a new pupil, but also a new girl in town, a stranger in the socio-cultural sense, as we see during the dinner party scene. These struggles add a certain poignancy to the fact that the character's philosophy of hospitality is deeply informed by her 
fascination with written texts. Currie deftly articulates how the act of writing is thematized in the novel:

Perhaps the most obvious instance of this internalization, or thematization of writing is the figure of Miles Garth himself, who is the silent and invisible centre of the novel's action, and reproduces on the inside the silence and blankness of its physical predicament as a book. He is, of course, also behind a threshold, the locked door of a bedroom into which he retreats, invisible and silent, like the future to come. (Currie 53)

Currie ignores an aspect that makes this contention incompatible with my own argument: Brooke also asks Miles to imagine himself: "I mean if you were in the room and you were exactly the same ages as me, and at the same time you're in the room too, old like you are" (There 53). Here, Brooke's deliberate circumvention of literary objectivization gives Miles agency. In turn, this fact allows for an analysis which sees the act of hospitality as the vehicle and the repository of the thematized writing process that Currie observes in the novel (54). Of course, writing itself is also a "staging" of welcoming the other. However, both sides of this dyad should be taken into account when relating futurity to writing. Hospitality is also something that goes deeper into the dawn of humanity and the first forms of communication than "writing" and "grammar" do (in a way, hospitality could be one more phenomenon which bridges our imagined gap of "personhood" between the human and the rest of the living world). Smith's novels illustrate precisely this moment where hospitality takes on language, as it is haunted by the future from before its inception, and the future itself is haunted by the sense of an alterity.

Various changes occur in the relation between Brooke's perception of futurity and the deixis in scenarios of hospitality, as the novel foregrounds the space within which this relation is established in the subject's consciousness. When her parents talk to her regarding the teacher's notes he gets for truancy. Terence, her father, proffers an invitation: "Imagine you are here with yourself, only yourself is my age, ... what would be the thing you would most need to tell her?" (177). However, she can only imagine herself through the heard and unheard stories of people that went before her. Her vision of futurity is not of herself as a stranger, but of herself as connected with and changed by all 
that has lived and lives around her. Thus, she decides not to tell on her intolerant teacher. She would rather keep her freedom and not attend the classes than to have her parents intervene for her and thus, lose some of her autonomy and consequently, free mobility. This will to agency is also something subconsciously encouraged by Miles's decision to lock himself in the Lees' spare-room. In this case, instead of explaining herself, Brooke rather asks her father to take her to the tunnel, where:

He and Brooke did the whistling thing, where one of you goes way ahead of the other and then listens for the really good way that whistling sounds bouncing off the tiles down there, which is especially good when you can't see the person who's whistling or tell what direction the whistling is coming from. By the time they got to the other end ... her father had forgotten what he was asking on the other side before they came down into the tunnel. So it was okay. (There 186)

We can read in this "punnel" (as she and Anna call it) another form of Derrida's choratic space, the arbitrariness of the linguistic sign Smith has been keen to problematize since Like. It is this space where the Event can take place, where the alterity comes in. Brooke also notes how when some clocks hit midnight, they indicate "nothing o'clock," which again, can hint at what Boxall was going to refer to seven years later as "an immanent futurity - the sense that we are surrounded by a latent, untensed time that we cannot quite grasp" (280). This void which contains the aporia of hospitality is the prism through which Brooke looks to the time that is to come. This is why she sees herself through the pop culture figures represented by white people ("The fact is, I can be Hermione if I like") as much as she does through all the people that have been unjustly killed throughout the centuries ("a boy who was historically murdered. If something is in the past, can it still be in the present or not?" (There 207). As she tries to fall asleep in her bedroom, her mind conjures up images of the people killed in their sleep during the Haitian earthquake, as well as of herself and her family being detained for two hours in an airport interrogation room, only to be set free without any explanation.

However, it is her visit to Miles's new dwelling that offers us a true display of hospitality. She is the first one to knock in months, which is why she can get in. She brings him tea from the Lees' kitchen. This visit 
and gift come as results of a profound ambivalence toward the concept of private property, though she will afterwards neatly put the cups back in place. Staring around the spare bedroom, she already ties this space to Miles and envisions it as a sanctuary to which she can return during her future absences from school. Will she again toe the line between autonomy and human connection, taking Miles's place? Will she visit him specifically? What can be deduced is that this selection of alterity involves a "scan[ning]" (There 74) that again takes us back to the choratic space.

Here, too, Garth responds to the linguistic output of the alterity in such a way that it makes space for her singularity as the unexpected Event. Her knock-knock jokes are reciprocated, as Miles then invites her to tell him anecdotes she finds interesting. However, his weary and tired demeanor denote a certain vulnerability which indicates that he himself is not sure how to envision his future anymore. His pause in human interaction might be a deliberate return back to the choratic space, from where invisibility and the Unexpected are concepts with which one can work to "how to walk a clean path between obscenities" (There 112). This man who dreamt of revolution as a teenager, and now works as an ethical consultant to big corporations is faced with the crux of consumption and financial gain under late-stage capitalism: how can we be hospitable to strangers we cannot see? How do we lessen the damage and injustices which maintain the lifestyles to which we have become accustomed? Interestingly enough, the aporia between conditional and unconditional hospitality turns up in one of Bernice's ethical puzzles she poses to Brooke: "you can enjoy a really lovely treat yourself, but because you do someone else somewhere will have to suffer. Or: you can choose to suffer with somebody who's also having a really difficult time, but because you do, the suffering will be easier for that other person" (There 209). Therefore, this dichotomy is what Brooke will have to keep in mind along with the arrival of the stranger: the presence of invisible, imperceptible, unknowable strangers that will inevitably, physically arrive, for whom she is morally responsible, and for whom she has to be able to fight. They, too, partake in the choratic space, though their power is subtler, and they, too, are affected by what arrives in the choratic space of those in more privileged. Given this acknowledgement, Brooke is by far the most 
revolutionary character in the text. Of course, her references to President Obama, global warming and the Greenwich port, have all undergone a dark, dismal change of tone in the wake of Trump's election, the galloping effects of climate change, and obviously, the Brexit vote. However, this only serves to increase the relevancy of Brooke's epistemological system regarding the "up rising" she broods over as she is reminded of her teacher. Here, though, we should remind ourselves that Miles himself told Anna he was singing "revolution," not ABBA ("I believe in Engels") (There 38) when he was still in secondary education. Once again, a dichotomy of possible developments is encrypted in Brooke's future.

Aside from radically hospitable outcomes, the choratic space may also generate hostility, most vividly illustrated at the Lees' dinner party: they have a craving for guests of "exotic" identities but do not want to find out anything about them that does not fit their preconceptions regarding the respective guests' experiences. Therefore, though the Lees are confronted with the unexpected event of an uninvited guest locking himself up in their spare bedroom, their fake universalism, founded on tokenism and condescending virtue signaling, reveals the innate possible hostility that looms over the act of hospitality itself, and other acts of hospitality to which it might lead, which is its potential manufacturability and exploitability. True hospitality pays heed to the singularity of the other. Smith's novel depicts the empathetic peaks and passively destructive pitfalls that are latent in this inescapable dimension of ethics.

\section{Conclusion}

There But For The foregrounds the self's continuously changing relation to the figure of future strangers, as their arrival tests the host's ability to accommodate their absolute singularity. Consequently, Smith's narrative ethics offers a mode of knowledge that helps us internalize this awareness of the unexpected, imminent, disorienting event of welcoming, which will be guided by our responsible rationalization of the stranger's futurity. I have analyzed scenes pertaining to hospitality and have found deictic, thematic, linguistic, and subtextual elements which relate them to the theme of futurity, while also consequently encoding the scenario of 
welcoming into the expected and unexpected Events to come. It is these very roots in futurity that can help us distinguish truly ethical acts of hospitality from illusionary, predatory constructions of welcoming scenarios, which aim to exploit stranger and oblivious host alike.

\section{Works Cited}

Attridge, Derek. The Work of Literature. Oxford: Oxford UP, 2015.

Currie, Mark. "Ali Smith and the Philosophy." Ali Smith: Contemporary Critical Perspectives. Ed. Monica Germana and Emily Horton. London: Bloomsbury Academic, 2013. 48-61.

Boxall, Peter, ed. The Cambridge Companion to British Fiction: 1980- 2018. Cambridge: Cambridge UP, 2019.

Derrida, Jacques and Anne Dufourmantelle. Of Hospitality. Trans. Rachel Bowlby. Stanford: Stanford UP, 2000.

---. Rogues: Two Essays on Reason. Trans. Pascale-Anne Brault. Stanford: Stanford UP, 2005.

---. Specters of Marx: The State of the Debt, the Work of Mourning and the New International. Trans. Peggy Kamuf. New York: Routledge, 1994.

Dick, Maria-Daniella and Julian Wolfeys. The Derrida Wordbook. Edinburgh: Edinburgh UP, 2003.

Levinas, Emmanuel. Otherwise than Being, or, Beyond Essence. Trans. Alphonso Lingis. Pittsburgh: Duquesne UP, 1998.

---. Time and the Other. Trans. Richard A. Cohen. Pittsburgh: Duquesne UP, 1987.

O'Donnell, Patrick. "The Space That Wrecks our Abode: The Stranger in Ali Smith's Hotel World and The Accidental." Ali Smith: Contemporary Critical Perspectives. Ed. Monica Germana and Emily Horton. London: Bloomsbury Academic, 2013. 89-100.

Smith, Ali. There But For The. London: Hamish Hamilton, 2011.

---. Autumn. London: Hamish Hamilton, 2011. 